\title{
Intravitreal anti-VEGF therapy in macular oedema secondary to racemose haemangiomatosis of the retina
}

\author{
Magdalena Tylus, Jerzy Mackiewicz, Joanna Dolar-Szczasny, Anna Święch-Zubilewicz \\ Department of Vitreoretinal Surgery, Medical University in Lublin, Lublin, Poland
}

\begin{abstract}
Racemose haemangiomatosis of the retina is a sporadic, mostly unilateral, congenital arteriovenous malformation (AVM), comprising abnormal junctions between arteries and veins that omit capillaries. Typically, vascular malformations are asymptomatic and incidentally discovered. Advanced changes may be related to the presence of subretinal fluid and exudates, even though these lesions are classified as benign. Many complications can lead to severe or permanent visual impairment. Direct methods of treatment of primary retinal vascular anomalies have not been developed yet. The aim of this case report is to present the anti-VEGF therapy in the treatment macular oedema secondary to racemose haemangioma.
\end{abstract}

KEY WORDS: racemose haemangiomatosis, anti-VEGF, macular oedema, intravitreal injection

Ophthalmol J 2017; Vol. 2, No. 2, 58-60

\section{INTRODUCTION}

The vascular tumours of the retina comprise a diverse group of congenital and acquired lesions, that include capillary haemangioma, cavernous haemangioma, racemose haemangiomatosis, and retinal vasoproliferative tumour $[1,2]$.

Racemose haemangiomatosis of the retina is a sporadic, mostly unilateral, congenital arteriovenous malformation (AVM), comprising abnormal junctions between arteries and veins that omit capillaries. If similar vascular malformations coexist in the same side of the brain, that relation is considered as a Wyburn-Mason syndrome (also known as Bonnet-Dechaumme-Blanc syndrome). Lesions may also be located in the skin, bones, muscles, kidneys, and in gastrointestinal tract [3, 4]. Typical clinical manifestation reveals characteristic dilated and tortuous retinal vessels that can extend from the optic disc to the retinal periphery [5]. Depending upon the severity of the vascular malformation, they are classified into three distinct groups: Group I AVMs possesses abnormal capillary plexus between the large vessels; Group II shows a lack of capillary vessels; and Group III includes the most extensive AVMs, with dilated and tortuous vessels [6].

Fluorescein angiography (FA) demonstrates anomalous arteriovenous communications and the hyperfluorescense without leakage (Fig. 1). Typically, vascular malformations are asymptomatic and incidentally discovered. Bigger changes may be related with the presence of subretinal fluid and exudates. In the diagnosis and monitoring of the disease, optical coherence tomography (OCT) is found to be useful [7].

Anti-VEGF therapy is an option in managing complications of retinal arteriovenous anomalies [8].

\section{CASE REPORT}

A 41-year-old female patient reported to the Department of Vitreoretinal Surgery of the Medical 

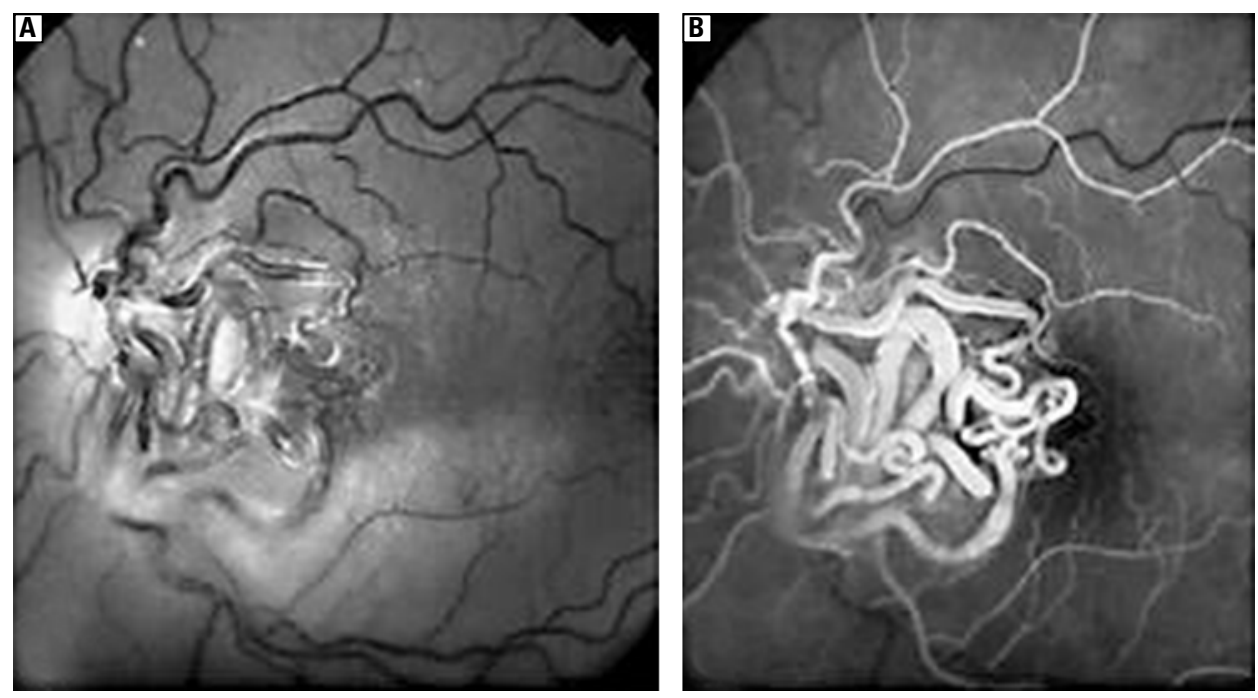

FIGURE 1. Fluorescein angiogram (FA) of the right eye. A. FA image showing arteriovenous malformations. B. FA image confirm the characteristic absence of leakage from the AVMs

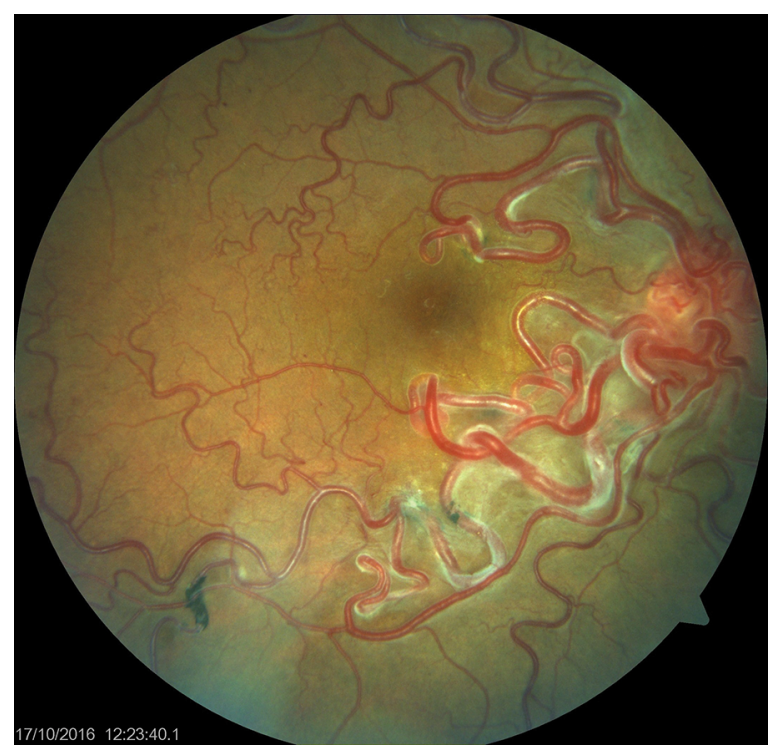

FIGURE 2. Colour photography of the right eye fundus - racemose haemangiomatosis of retina

University in Lublin complaining about deterioration of vision in her right eye. In a clinical examination, we found that the best corrected visual acuity (BCVA) in the right eye was 0.3 , and in the left eye - 1.0. Examination of the anterior segment of the both eyes with a slit lamp showed no abnormalities. Fundus examination of the right eye revealed the presence retinal racemose haemangioma (Fig. 2) and secondary macular oedema. OCT of the right eye showed cystoid macular oedema (CMO) (Fig. 3).

The patient was qualified to intravitreal injection of anti-VEGF (Vascular Endothelial Growth Factor) - bevacizumab to her right eye. One month

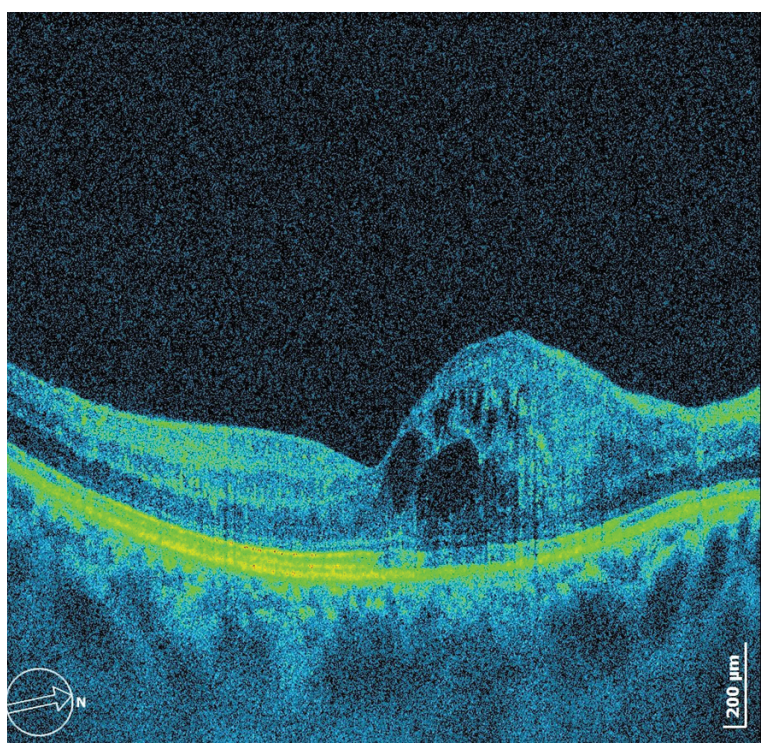

FIGURE 3. Optical coherence tomography image of the right eye — macular oedema

after intravitreal injection of bevacizumab, BCVA in the right eye improved, reaching 0.8. Fundus examination and OCT of the right eye revealed no macular oedema. After two months of observation the patient achieved full visual acuity. OCT examination showed complete absorption of subretinal fluid (Fig. 4).

\section{DISCUSSION}

Retinal vascular malformations are benign, usually asymptomatic, and discovered incidentally during ophthalmologic examination. However, in 


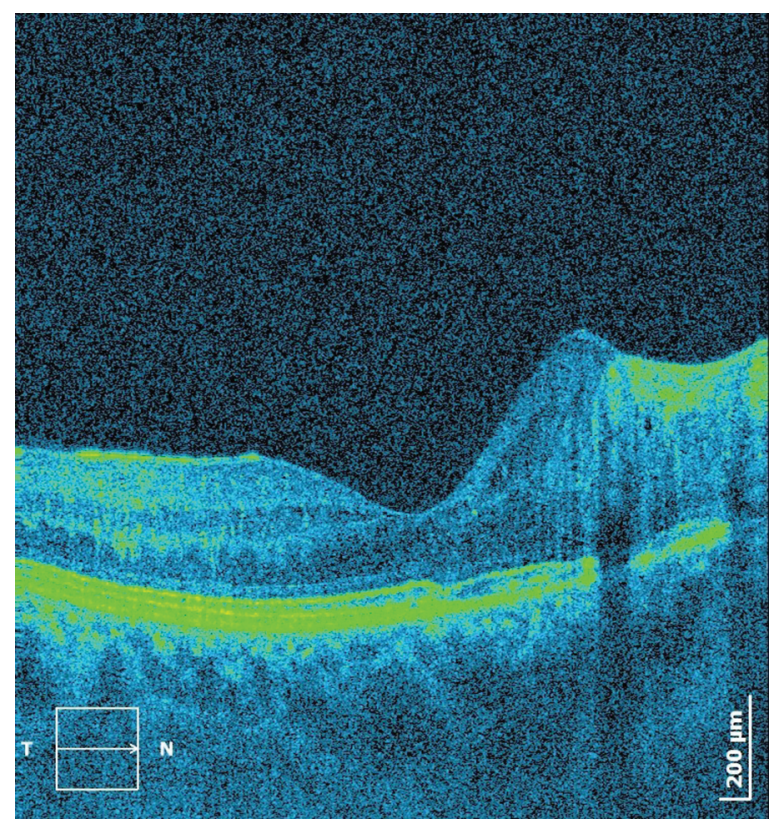

FIGURE 4. Optical coherence tomography image of the right eye, showing complete elimination of subretinal fluid after anti-VEGF injection

many cases, they can cause significant deterioration of vision by various mechanisms. Blood vessels tortuosity can lead to the closure of their barrel $[9,10]$, retinal ischaemia [11], and neovascular glaucoma [12]. It can also lead to macular haemorrhage, serous pigment epithelium detachment, and cystoid macular oedema [13, 14].

Direct methods of treatment of primary retinal vascular anomalies have not been developed yet. Only the above-mentioned complications are covered by the treatment. In 2006 Soliman et al. described a case of treatment of a patient with bilateral racemose haemangioma by photocoagulation of the vascular leakage points [15]. However, considering the age of patients, the incidence of CMO near the fovea, and the risk of subretinal choroidal neovascularization, which entails photocoagulation, treatment with anti-VEGF preparations is much safer [16].

Currently, the literature describes one case of treatment $\mathrm{CMO}$ in the course of retinal racemose haemangioma by intravitreal injection of bevacizumab [16]. The exact mechanism of action in this case is unknown; however, by decreasing the vascular permeability and increasing the number of tight junctions between proteins a significant reduction of subretinal fluid was obtained [16].

In our case intravitreal injection of bevacizumab resulted in complete regression of the CMO in the right eye, which was associated with the return of full visual acuity. The therapy applied in this case was a safe and effective method against cystoid macular oedema in the course of retinal racemose haemangioma. At the time of writing, after six months of observation, the macular oedema has not recurred. However, patients with racemose haemangiomatosis of the retina should be carefully monitored because such treatment is directed towards secondary retinal changes, not to the primary disease.

\section{REFERENCES}

1. Turell ME, Singh $A D$. Vascular tumors of the retina and choroid: diagnosis and treatment. Middle East Afr J Ophthalmol. 2010; 17(3): 191-200, doi: 10.4103/0974-9233.65486, indexed in Pubmed: 20844673.

2. Knutsson KA, De Benedetto U, Querques G, et al. Primitive retinal vascular abnormalities: tumors and telangiectasias. Ophthalmologica. 2012; 228(2): 67-77, doi: 10.1159/000338230, indexed in Pubmed: 22738997.

3. Wyburn-Mason R. Arteriovenous aneurysm of midbrain and retina, facial, nevi and mental changes. Brain. 1943; 66(3): 163-203, doi: 10.1093/brain/66.3.163.

4. Théron J, Newton TH, Hoyt WF. Unilateral retinocephalic vascular malformations. Neuroradiology. 1974; 7(4): 185-196, indexed in Pubmed: 4547345.

5. Szaflik J, Starzycka M. Patologia narządu wzroku i guzy wewnątrzałkowe. Seria Basic and Clinical Science Course (BCSC 4). Urban\&Partner, Wrocław 2003: 263.

6. Archer DB, Deutman A, Ernest JT, et al. Arteriovenous communications of the retina. Am J Ophthalmol. 1973; 75(2): 224-241, indexed in Pubmed: 4697179.

7. Heimann H, Jmor F, Damato B. Imaging of retinal and choroidal vascular tumours. Eye (Lond). 2013; 27(2): 208-216, doi: 10.1038/ eye.2012.251, indexed in Pubmed: 23196648.

8. Kenawy N, Groenwald C, Damato B. Treatment of a vasoproliferative tumour with intravitreal bevacizumab (Avastin). Eye (Lond). 2007; 21(6): 893-894, doi: 10.1038/sj.eye.6702782, indexed in Pubmed: 17347676.

9. Shah GK, Shields JA, Lanning RC. Branch retinal vein obstruction secondary to retinal arteriovenous communication. Am J Ophthalmol. 1998; 126(3): 446-448, indexed in Pubmed: 9744380.

10. Oin Xj, Huang C, Lai K. Retinal vein occlusion in retinal racemose hemangioma: a case report and literature review of ocular complications in this rare retinal vascular disorder. BMC Ophthalmol. 2014; 14: 101, doi: 10.1186/1471-2415-14-101, indexed in Pubmed: 25142779.

11. Panagiotidis D, Karagiannis D, Tsoumpris I. Spontaneous development of macular ischemia in a case of racemose hemangioma. Clin Ophthalmol. 2011; 5: 931-932, doi: 10.2147/OPTH.S21925, indexed in Pubmed: 21792280.

12. Effron L, Zakov ZN, Tomsak RL. Neovascular glaucoma as a complication of the Wyburn-Mason syndrome. J Clin Neuroophthalmol. 1985; 5(2): 95-98, indexed in Pubmed: 2432092.

13. Sanfilippo CJ, Sarraf D. Congenital macrovessel associated with cystoid macular edema and an ipsilateral intracranial venous malformation. Retin Cases Brief Rep. 2015; 9(4): 357-359, doi: 10.1097/ ICB.0000000000000236, indexed in Pubmed: 26421894.

14. Onder HI, Alisan S, Tunc M. Serous retinal detachment and cystoid macular edema in a patient with Wyburn-Mason syndrome. Semin Ophthalmol. 2015; 30(2): 154-156, doi: 10.3109/08820538.2013. 835832, indexed in Pubmed: 24171831.

15. Soliman W, Haamann P, Larsen M. Exudation, response to photocoagulation and spontaneous remission in a case of bilateral racemose haemangioma. Acta Ophthalmol Scand. 2006; 84(3): 429-431, doi: 10.1111/.1600-0420.2005.00644.x, indexed in Pubmed: 16704713.

16. Winter E, Elsås T, Austeng D. Anti-VEGF treating macular oedema caused by retinal arteriovenous malformation - a case report. Acta Ophthalmol. 2014; 92(2): 192-193, doi: 10.1111/aos.12019, indexed in Pubmed: 23241246. 